\title{
Arte e ideología en la estética abierta de Adolfo Sánchez Vásquez
}

Fecha de entrega: 10 de mayo de 2018

Fecha de evaluación: 7 de junio de 2018

Fecha de aprobación: 30 de junio de 2018

Miguel Rojas Gómez ***

\section{Resumen}

En el artículo, se sigue el objetivo de revisar los planteamientos del español radicado en México, Adolfo Sánchez, fallecido en 2011, luego de una destacada actividad investigativa en la Universidad Nacional Autónoma de México (UNAM). Sus reflexiones en torno a la estética de Marx llevaron a Sánchez a plantear asuntos como la praxis de la creación artística, en que el realismo socialista que busca el reflejo del mundo y la ideología en la obra resulta perjudiciales para la tarea estética e, incluso, pueden coartar la libertad del creador. Sánchez se preocupa por incluir en la praxis estética la acción interpretativa del lector en que el placer por una obra nos conecta con la significación de lo humano, raíz del sentido de la belleza. De tal modo, en la expresión estética de una obra, las mediaciones culturales e ideológicas no se dan ausentes, ya que las ideas culturales, políticas o filosóficas dejan huellas en la creación del artista.

Palabras clave: praxis, estética, marxismo, ideología, belleza, creatividad.

* Citar como: Rojas G., M. (2018). Arte e ideología en la estética abierta de Adolfo Sánchez Vásquez. Cuadernos de Filosofía Latinoamericana, 39(119), 113-135. DOI: http://www.doi. org/10.15332/25005375.5053

* Doctor en Ciencias Filosóficas, (Cuba). Profesor Facultad de Bellas Artes de la Universidad Pedagógica Nacional de Colombia, Bogotá, Colombia. Correo: mrojasg@pedagogica.edu.co 


\section{Art and ideology in the open aesthetics of Adolfo Sánchez Vásquez}

\section{Abstract}

The text follows the objective of reviewing the approaches of Adolfo Sánchez, Spanish resident in Mexico, who died in 2011, after an outstanding research activity at UNAM. His reflections on the aesthetics of Marx led Sanchez to raise issues such as the praxis of artistic creation, where the socialist realism that seeks the reflection of the world and the ideology in the work, are detrimental to the aesthetic activity and can even coerce the freedom of the creator. Sanchez is concerned to include in the aesthetic praxis the interpretative action of the reader where the pleasure for a work connects us with the meaning of the human, root of the sense of beauty. So in the aesthetic expression of a work the cultural and ideological mediations are not absent, since cultural, political or philosophical ideas leave traces in the creation of the artist.

Keywords: praxis, aesthetics, Marxism, ideology, beauty.

\section{Introducción: las dimensiones de la estética más allá de los ismos}

Una de las principales personalidades del quehacer teórico desde América Latina durante la segunda mitad del siglo XX y el primer lustro de la actual centuria fue sin duda Adolfo Sánchez Vázquez (1915-2011), español radicado en México a consecuencia de la Guerra Civil Española. Aquí, en la Universidad Nacional Autónoma de México (UNAM), completó su formación iniciada en la entonces Universidad Central de Madrid hasta alcanzar el Doctorado en Filosofía. A su vez, se convirtió en uno de los más relevantes profesores e investigadores de la UNAM, cuya obra trascendió tanto a nivel nacional como internacional. Dejó - desde la filiación al marxismo abierto y antidogmático, en diálogo enriquecedor con otras corrientes teóricas de pensamiento- una vasta obra que abarca la filosofía, la filosofía de la praxis, la filosofía política, la ética, la estética y el arte, entre las principales. 
Desde finales de la década de 1950, intentó abrir nuevas brechas en la "dura" roca de la estética marxista soviética, pero no acaba de romper con el marco teórico "ortodoxo" (Sánchez, 2004b, p. 36), como él mismo confesó años después. Da cuenta de este proceso su tesis de maestría Conciencia y realidad en la obra de arte, defendida en 1957, en la Facultad de Filosofía y Letras de la UNAM. La ruptura significativa comenzó en la siguiente década, al publicar las Ideas estéticas en los Manuscritos económicos y filosóficos de Marx, de 1961, prolegómenos de su libro Las ideas estéticas de Marx, de 1965, en que se sustenta una estética abierta, en actitud plural ante el arte, las distintas teorías estéticas marxistas y occidentales. En este itinerario estético, no se puede omitir su libro Filosofía de la praxis, de 1967, fruto de su tesis de doctorado defendida en 1966. Texto revisado y ampliado para su segunda edición de 1980. Vale destacar que en este clásico libro Sánchez Vázquez analiza entre los tipos de praxis la creación artístico-estética.

Posteriormente, en el campo disciplinar de la estética y el arte, vendrían otros importantes títulos como Estética y marxismo, dos tomos, de 1970; Textos de estética y teoría del arte, de 1972; Ensayos sobre arte y marxismo, de 1984; Invitación a la estética, de 1992; Cuestiones estéticas y artísticas contemporáneas, 1996; De la estética de la recepción a la estética de la participación, de 2005, entre los principales, sin obviar varios artículos y ensayos sobre la estética y el arte, como los que aparecen en A tiempo y destiempo: antología de ensayos, de 2004. Igualmente, no se puede omitir su creación poética, pues, como subrayó Ramón Xirau, también "Sánchez Vázquez es poeta, y buen poeta” (2004, p. 8). Escribió el Pulso ardiendo, de 1942, y Poesía, de 2005. Aquí se encuentran poemas de protesta política y justicia social, al igual que sobre el amor; se entretejen lo lírico y lo social.

De particular importancia en el orden histórico teórico resulta la antología Estética y marxismo, en la cual, no solo compiló las diferentes tendencias y actitudes estéticas de los distintos marxismos hasta entonces, década de 1970, sino también por la valoración crítica explicitada y los comentarios introductorios a cada selección y autor. Destacó que, en la estética marxista soviética de entonces, se pensó, erróneamente, que la esencia del arte como núcleo principal de la estética radicaba en la ideología política y en el reflejo, como lo manifestaron el zhdanovismo y el estalinismo, concepción antecedida por los criterios de Gueorgui Valentínovich Plejánov sobre el arte y la literatura. Mala y dañosa teoría oficiosa que fue asumida por la generalidad de teóricos de la estética del realismo socialista, aun en aquellos de más amplia mira, 
como Moisei S. Kagan (cfr. Kagan, 1984). Por oposición a ese escolasticismo, Sánchez Vázquez destacó otras posturas, cuatro posiciones estéticas marxistas fundamentales (cfr. Kagan, 1984) respecto del arte: a) como conocimiento específico (Georg Lukács, A. Búrov), b) diversión o placer estético sin obviar la dimensión social y política (Bertolt Brecht), c) como sistema de signos y medios expresivos (Galvano Della Volpe, Stefan Morawski) y d) actividad práctico-productiva (M. S. Kogan, Nóvik), con inclusión del propio Sánchez Vázquez en esta última tendencia, sin obviar otros como Lucien Goldmann, Ernst Fischer, Louis Althusser o Roger Garaudy. Todos, sin obviar limitaciones, expusieron de modo más coherente que la estética marxista leninista soviética las mediaciones entre la ideología política y el arte. En este sentido, Sánchez Vázquez subrayó que “ellos se alejaron de las tesis simplistas que ven el arte como una ilustración de la ideología [política] o que reducen el valor de una obra al de las ideas plasmadas en ellas" (1978, p. 33).

Más allá de la clasificación misma y de los teóricos analizados, con omisión de otros exponentes de las teorías estéticas marxistas, como los casos latinoamericanos (cfr. Rojas, 1996, pp. 194-212; Rojas, 1998, pp. 79-111) de José Antonio Portuondo (cubano) o Héctor Pablo Agosti (argentino), lo más significativo lo constituye la demostración que existían otras versiones estéticas sobre el arte y la realidad que intentaban dar cuenta de un modo diferente de como lo hacía la codificación de la estética marxista leninista soviética. En este orden, Portuondo puntualizó que la posición "más justa resulta el punto de vista de Sánchez Vázquez" (1979, pp. 105-106).

El destacado profesor-investigador en diálogo permanente y en polémicas enriquecedoras con las estéticas de los diferentes marxismos, como el realismo de vía estrecha de Lukács o el realismo ecuménico "sin riberas” de Roger Garaudy y las estéticas occidentales del siglo XX, desarrolló una concepción estética auténtica que ha devenido una aportación indispensable para la comprensión de la teoría estética contemporánea que incluye en su objeto el arte, aunque no se concluye en él, como puntualizó. Subrayó que esta

debe ser una teoría abierta en un sentido doble: a) dispuesta a la discusión con otras teorías estéticas, $y$, en primer, lugar con las que no coinciden con ella dentro del propio campo marxista, y b) dispuesta a admitir como un objeto de investigación y explicación los cambios que se operan en la práctica artística y la sociedad. (Sánchez, 1978, pp. 72-73) 
En consecuencia, por muy aportativa que sea una estética, nunca agota la diversidad y riqueza del arte y la realidad, ${ }^{1}$ en constante desarrollo, por lo que la estética debe ser una estética abierta de y para la libertad creadora y, por consiguiente, no prescriptiva. Las estéticas particulares, todas, confluyen hacia la Estética, con mayúscula, complementándose unas a otras.

Al debatir con las teorías del arte y las estéticas del siglo XX, defendió el criterio que "la Estética es la ciencia de un modo específico de apropiación de la realidad, vinculada con otros modos de apropiación humana del mundo, y con las condiciones históricas, sociales y culturales en que se da [en cursiva en el original]" (Sánchez, 1992, p. 57). Conceptuación muy genérica; no obstante, en su Invitación a la estética, en más de cincuenta páginas, dio más concreción al postulado teórico-abstracto. Abordó con más detenimiento el espectro del objeto de la estética como disciplina, al plantear que lo estético tiene como uno de sus principales aspectos o elementos el arte y su creación, pero es mucho más, pues comprende igualmente la experiencia estética en relación con lo naturaleza, ya sea un paisaje, una flor o un animal, como el colibrí. Asimismo, las valoraciones en torno a las artesanías, ya sean griegas o mexicanas, de otra nacionalidad o etnia, las creaciones de carácter técnico como un automóvil, un avión u otro artefacto industrial de carácter utilitario, una persona ubicada en una cultura, etnia o tipo de sociedad, la vida privada o pública, lo cotidiano, el trabajo, la calle o el hogar.

Por tanto, para él la estética es mucho más que la filosofía del arte. Toda valoración de la realidad, toda creación humana en su multiplicidad de formas, puede estimarse estéticamente, aunque lo estético no sea la función rectora. Destacó que "lo estético puede darse para nosotros en a cualquier tiempo, en cualquier lugar, y cualquiera [que] sea la función extraestética que el objeto pueda cumplir, junto con su función estética" (Sánchez, 1992, p. 17). De este modo, sostiene una teoría general de la estética, pero, a diferencia de las estéticas especulativas o meramente filosóficas y abstractas, argumentó que la teoría debía validarse en el objeto estético concreto, sin soslayar que esta implica lo teórico-metodológico desde la dimensión heurística, en doble sentido de co-implicación, es decir, tanto por el carácter de postulación de la estética como estética abierta como por la comprensión de la obra de arte como obra abierta

1 Edgar Carrit sostiene que "es artificiosa, [...], la bisección. No hay dos [posiciones estéticas] sino millones de actitudes con respecto al mundo [y el arte], variadisimas en amargor y dulzor: curiosidad, deseo, desmayo, rebelión, odio, desesperación, confianza en Dios, temor religioso, materialismo optimista, etcétera" (1983, p. 65). 
(Eco, 1984). Concepción que va desde Las ideas estéticas de Marx, de 1966, hasta De la estética de la recepción a la estética de la participación, de 2005, su último libro.

Sostendrá que

el texto solo es obra por la actualización o concreción que lleva a cabo el lector [u oyente]. El texto es, pues, una premisa básica o condición necesaria insoslayable para constituir o producir la obra. O análogamente: sin recepción [Warning, 1989], no hay producción (de la obra). (Sánchez, 2005, p. 67)

En convergencia con Wolfgang Iser y Hans Robert Jauss, exponentes de la estética de la recepción, precisó que "la obra es más que el texto" (Sánchez, 2005, p. 66), como actualización de este, pone en este lo que no está en aquel, por lo que, en el caso de la partitura o una obra plástica, puede afirmarse que la auténtica interpretación es más que el texto. Señaló, a su vez, que el receptor debe ser un partícipe activo, por lo que es cocreador, de ahí su tesis de la estética de la recepción a la estética de la participación. Subrayó que "una obra, por tanto, no es algo cerrado en sí, sino lo que se ha dicho de ella, pero un decir que no se acaba en el presente sino que continúa en el futuro" (p. 33). Hay fusión de horizontes, del pasado y del presente, el que porta la obra y el del receptor-participante como cocreador.

Incluso Sánchez Vázquez, en “La utopía de Don Quijote”, de 1990, coincide con Iser al destacar que "las preguntas, para que puedan ser contestadas, tienen que estar dirigidas a las obra misma, es decir, a un objeto que, una vez producido, adquiere una vida propia y, por ello, sobrevive a - y se independiza de - la vida de su autor" (2004f, p. 532). No obstante, también hay diferencias con el teórico alemán de la estética de la recepción, por cuanto Iser niega el condicionamiento histórico de la obra de arte, mientras tanto el hispano-mexicano señaló que, "si la crítica es, ante todo, examen de la obra como objetivación de la actividad creadora[,] no puede hacer abstracción del examen de las condiciones en que esa actividad se halla obstaculizada por el modo peculiar de producción, distribución y consumo artísticos" (Sánchez, 1984h, p. 151). Su tesis es que toda obra de arte nace condicionada por su sociedad, época, por su espacio y tiempo, aunque trasciende estos por su capacidad de dialogar con otros tiempos y circunstancias, por su potencialidad semióticohermenéutica como obra abierta, por lo que su criterio se basa en la axialidad de historicidad y autonomía de la obra de arte. 
En la sustentación de la estética abierta, reconoce las contribuciones de la teoría del arte en cuanto que aborda la obra de arte como un todo; habría que decir como un todo abierto y concreto en lo cultural y en lo social. Sin embargo, como generalidad, la teoría del arte no investiga ni explica el carácter estético de la obra de arte o, en algunos casos, identifica la estética con belleza. Aquí también se detiene su examen analítico a cuestionar tanto la centralidad absoluta de identificar la estética con la belleza como a aquellos que en diferentes momentos históricos proclamaron su obsolescencia o muerte, como también se ha proclamado más de una vez la muerte del arte (Sánchez, 1984g) en "funerales teóricos" fallidos.

Al tematizar estas diferentes disyuntivas, con sus unilateralidades y parcialidades, argumentó:

Finalmente, a las dificultades que presenta — como acabamos de ver- la introducción de lo bello como concepto central de la definición de la Estética, hay que agregar las que plantea la creación artística misma. Si bien es cierto - como ya hemos subrayado- que durante siglos la belleza ha presidido la creación artística, no siempre ha sido así a lo largo de la historia del arte. Y no lo es, sobre todo, en la época contemporánea [...]. En suma, si la Estética no puede dejar de tener presente la historia real y si otros valores estéticos desplazan al de lo bello, no puede hacer de este su objeto central. En consecuencia hoy menos que nunca cuando el arte y los artistas lo arrojan por la borda, después de haberle rendido culto durante siglos, la Estética no puede definirse como la ciencia de lo bello. (Sánchez, 1992, p. 51)

Tenemos, pues la Estética como ciencia de la bello. Las dificultades de esta definición derivan precisamente del lugar central que en ella ocupa [o ha ocupado] lo bello. Fuera de él queda lo que no se encuentra en las cosas bellas: no solo su antítesis - lo feo-, sino también lo trágico, lo cómico, lo grotesco, lo monstruoso, lo gracioso, [lo sublime], etcétera; es decir, todo lo que sin ser bello no deja de ser estético. (Sánchez, 1992, p. 49)

Puntualizó que lo bello pertenece a lo estético, pero no todo lo estético es bello, porque, como destacó según la historia del arte y la creación artística (sin eludir las teorizaciones de filósofos, artistas, teóricos del arte, psicólogos, semiólogos, etc.), existen otras categorías también "tradicionales” de la estética, como lo feo, lo sublime, lo trágico, 
lo grotesco, lo cómico, y sus géneros o formas principales, como el humor, la farsa, la parodia, la sátira y el sarcasmo. Categorías a las que dedica atención en la relación de teoría conceptual, caracterización y demostración fáctica explicativa en las artes. No es casual que acotase que, "en el estudio de las categorías [,] hemos rehuido las definiciones abstractas, apriorísticas, que tanto abundan en las estéticas tradicionales, y hemos partido de lo que nos ofrece históricamente la experiencia estética y la práctica artística” (Sánchez, 1992, p. 20).

Es de lamentar que el capítulo dedicado a lo cómico en Invitación a la estética omitiera una categoría tan importante en las modalidades de lo cómico como el sarcasmo. Y en cuanto a lo bello no abordase maneras o "tipos" suyos como la hermosura, lo lindo, lo bonito y lo gracioso, esta última enunciada en sus análisis, al parecer como si fuese diferente de la belleza, y no reapareciera en temas o capítulos, como el dedicado a lo bello. Codificaciones relativas de lo bello que otros estetas abordan (Plazaola, 1999, pp. 336-358), aunque no es muy común en las estéticas contemporáneas, pero que en la práctica valorativa del arte, la cultura y la vida cotidiana se utilizan.

El diapasón en cuanto a la meditación del objeto de la estética ${ }^{2}$ en Sánchez Vázquez es bastante amplio y coherente, como se ha venido demostrando, aunque también forman parte de su corpus estético otras categorías como la experiencia estética (algunas veces referidas sin detallar especificidad), la percepción artística, las funciones del arte en la perspectiva de la polifuncionalidad, el valor y la valoración estéticas, la crítica (Sánchez, 1984a, pp. 140-151) teórica y del arte, los tipos de ideología que median en las complejas relaciones con la obra de arte, desde la ideología política general hasta la ideología estética y artística, recepción participante creadora, la producción o creación artística como tipo de praxis entre las principales. Unas implícitas y otras explícitas, que ameritan una investigación que desborda in toto los objetivos de este ensayo.

No obstante, es importante acotar que en la estética sanchevazquiana la producción o creación como praxis artística tiene un lugar central. Puntualizó que la creación artística como praxis se diferencia de otros tipos de práctica en cuanto que el arte

2 Al referirse al objeto de la estética, Wolfgang Welsh planteó que este "debiera trascender la identificación tradicional de estética y arte", sin negar a este último como uno de los principales componentes de su objeto, pero no el único. Asimismo, subrayó el imperativo que debiera ser también "un campo de investigación que abarque todas las cuestiones relacionadas [...] con la inclusión de contribuciones de la filosofia, la sociología, la historia del arte, la psicologia, la antropologia, las neurociencias, y así sucesivamente. La aisthesis constituye el marco de la disciplina" (2011, pp. 28 y 31 ). 
caracteriza, "no ya una necesidad práctico-utilitaria, sino una necesidad humana de expresión y comunicación” (Sánchez, 1980, p. 240), en la cual la obra produce una socialización de la creación como una exigencia estética y social. El arte es doblemente social (Sánchez, 1966, p. 232). Siendo una creación individual e irrepetible, es la creación de un individuo socialmente condicionado. Por otra parte, la obra de arte, no solo satisface la necesidad de expresión de su creador, sino también de otros. Superó el enfoque tradicional y planteó que entre la obra y el “espectador" se abre una relación estética creadora (Sánchez, 2005), porque este se incorpora al proceso mismo de creación, o sea, es cocreador y no mero espectador inmutable, aunque a veces aparece en su terminología el concepto de contemplación, reminiscencia de la estética tradicional que él mismo impugna. A pesar de esta inconsecuencia, lo dominante y tendencial es la sustentación que el mal llamado "espectador" o "contemplador" es también partícipe de la creación. Esta es una tesis raigal apreciable desde Las ideas estéticas de Marx, apreciable en el conjunto de textos que dedicó a la estética y al arte.

En este orden de reflexión sobre la creación artística, en correlación epistemológica y axiológica, examina lo estético como relación entre sujeto-objeto de manera concreta y situada, distanciándose de modo crítico de las tendencias objetivistas y subjetivistas de la axiología estética. ${ }^{3}$ Para él lo bello, lo feo, lo sublime, lo trágico, lo grotesco y lo cómico con sus varias formas son también valores que acontecen en una experiencia estética abierta y concreta, de acuerdo con su postura de la estética abierta. Precisó desde la década de 1960 que "el valor estético no es, por tanto, una propiedad o cualidad que los objetos [u obras de arte] tengan por sí mismo, sino algo que se adquiere en la sociedad humana y gracias al hombre como ser creador" (Sánchez, 1966, p. 95). Subrayó que "gozar o consumir un cuadro [o un objeto] es apropiarse de su significación humana, de su belleza, del contenido espiritual que a través de determinada forma

3 Uno de los importantes desarrollos actuales de la axiología estética aparece en la obra de José Ramón Fabelo, pudiendo destacarse su ensayo Apuntes para una interpretación axiológica del arte, de 2005. Destacó que el arte presupone la relación artista-obra-público, es decir, sujeto-objeto-sujeto, equivalente a lo que en la investigación del hecho artístico se subraya como proceso de relación subjetivación-objetivación-subjetivación. Asi plantea el axiólogo y esteta cubano: "La primera parte de esta relación (S[ujeto]-O[bjeto]) abarca el proceso de objetivación de la subjetividad del artista, concretado en el acto de la creación artística. La segunda parte de esta fórmula (0[bjeto]-S[jeto]) se refiere a la subjetivación nuevamente de la subjetividad objetivada en la obra, pero ya en esta ocasión no por el artista mismo, sino por el público destinatario del arte, 'consumidor' de la obra artística". Y Añadió, "estamos en presencia de un valor estético cuando un objeto cumple una función estética, [...] tenemos un valor artístico cuando cumple esta función que es dominante" (pp. 135 y 138). A su vez, esclareció que este último proceso puede generar un plus en la valoración estética de la obra de arte, es decir, actividad creadora del receptor-participante. 
ha objetivado en él su creador" (p. 228), es decir, a través de un acto de valoración estética multisémica. Explicitó que "lo decisivo aquí -en la valoración de la obra-es justamente no lo dado, sino lo creado" (Sánchez, 1984a, p. 146). Acto creador en su doble aspecto, el del artista y el del receptor-participante como cocredor.

Acotó que "la función estética es siempre indispensable en el arte, incluso, aunque éste pueda asumir otros valores y cumplir otras funciones" (Sánchez, 1984a, p. 146). En su lógica, la función estética, en la relación sujeto-objeto, sólo puede concretarse mediante la actividad creadora. Sostendrá criterios como los siguientes:

El arte es una actividad humana esencial. Las obras de arte son en primer lugar creaciones. En ellas, el hombre extiende, enriquece, la realidad humanizada por el trabajo y se eleva la conciencia de su dimensión creadora. Pero el arte no solo manifiesta esta dimensión del hombre, sino que sirve a otros fines, cumpliendo las funciones más diversas: mágica, religiosa, política, económica, etc. (Sánchez, 1984e, p. 120)

La praxis artística o el arte como actividad práctica específica o trabajo creador, desemboca en un resultado o producto también específico que llamamos recepción. (Sánchez, 2005, p. 19)

La nueva relación entre obra y consumidor altera radicalmente lo tradicional. El artista es creador en un doble sentido: a) como en el pasado: de una nueva realidad; b) de nuevas posibilidades de creación. La obra muestra prácticamente su valor en la medida en que es actualizada. Pero, a su vez, es fuente inagotable, y en este sentido, es una creación ininterrumpida o permanente. (Sánchez, 2005, p. 134)

Creación y finalidades a las que podrían agregarse otras muchas de acuerdo con el carácter multívoco de la obra de arte como obra abierta, como las funciones de concepción del mundo, cognoscitiva, heurística, antropológica, ético-moral, de previsión, libertaria, terapéutica, y así ad infinitum.

Está presente a través del entramado de su obra que los actos de valoración estética ${ }^{4}$ en la multisemia de significados y sentidos de que es portador la obra de arte, en

4 La valoración estética se puede conceptualizar como la relación del sujeto para con el valor estético, caracterizada por la subjetividad poiética del receptor-participante mediante la cual este desobjetiva 
concordancia con la polifuncionalidad, solo es posible a partir del prius de las funciones creadora, comunicativa y estética en interacción y mediación con aquellas consideras "extraestéticas". Resaltó que "el fin último de la obra de arte es ampliar y enriquecer el territorio humano. [...] satisface la necesidad específicamente humana de expresión y comunicación" (Sánchez, 1966, p. 114). La incomunicabilidad artística, lo inefable estético es, por consiguiente, la negación del arte, de su estimación, apreciación y valoración.

\title{
La obra de arte, las mediaciones ideológicas y el valor estético
}

En rechazo a contra todo posible socilogismo estético vulgar, Sánchez Vázquez declaró que "debemos guardarnos muy bien de transformar el criterio político en artístico, porque ello significaría medir por el rasero actividades que incluso estando relacionadas jamás llegan a identificarse” (1966, p. 266). Sin embargo, la comprensión de lo concreto artístico como conocimiento condicionado le permitió discernir con gran certeza el lugar de lo ideológico en el arte al indicar que la

\begin{abstract}
tesis marxista de que el artista se halla condicionado histórica, socialmente, y de que sus posiciones ideológicas desempeñan cierto papel — al que no es ajeno en algunos casos el destino de su creación - no implica, en modo alguno, la necesidad de reducir la obra a sus ingredientes ideológicos. Menos aún puede entrañar la exigencia de equiparar su valor estético con el valor de sus ideas. Incluso, cuando una obra de arte pone claramente al descubierto sus raíces de clase [otros grupos o etnias], seguirá viviendo aunque esas raíces, ya secas, no puedan dar nuevos frutos. La obra de arte rebasa así el humus histórico social que le hizo nacer. (p. 27)
\end{abstract}

\footnotetext{
la información, los significados estéticos del objeto a través la interpretación, la apreciación y la estimación intelectivo-emocional, la cual produce una expresividad que va desde los diferentes tipos de placeres catárticos, el desagrado, hasta la crítica, la confirmación o el rechazo. Por tanto, el gusto estético también forma parte de la valoración, así como la distancia critico-reflexiva ya enunciada por Charles Baudelaire y fundamentada por Bertolt Brecht. Proceso de valoración que en las artes del teatro y la música se hace más complejo por una valoración de "primer", "segundo" y $n$ "grados", dado que hay una "doble" o "triple" valoración, es decir, la del actor e intérprete y la del público receptor-participante, respectivamente (cfr. Rojas y Días, 2016, p. 124).
} 
La obra de arte gana autonomía respecto de las condiciones sociales en que se produjo, y depende de la lectura o valoración que pueda realizar un receptor participante en un aquí y ahora. Por tanto, el tiempo cronológico no las invalida, siempre tienen actualidad, de aquí que Walter Benjamin acuñase para el caso del arte el concepto de tiempo estético. No fue fortuito que en la Antigüedad clásica Hipócrates afirmase: ars longa, vita brevis. Por ello, si las ideologías de clases vienen, pasan y quedan olvidadas en determinadas sociedades, el arte auténtico lleva per se el sello de la sempiternidad y actualidad. Así ha sido con las pirámides de Egipto y el arte faraónico; las catedrales medievales; La comedia humana, de Balzac; Don segundo sombra, de Ricardo Güiraldes; las sinfonías de Wagner como Así habló Zarathustra; y será con lo mejor de las obras de Mario Vargas Llosa o Jorge Luis Borges, sus valías estético-literarias perdurarán en tanto sus ideologías político-conservadoras pasarán un día al olvido.

En la actualidad algunos posmodernos han declarado la muerte de la ideología política, sobre todo aquella que tiene que ver con lo que Lyotard (1991, pp. 9, 11, 70, 86, 108; cfr. Foster, 1998, pp. 7-17) llama relatos y metarrelatos, asistiéndole parte de razón, pero no la razón completa, mucho más refiriéndose al arte. A estos criterios habría que contestar cómo respondió el gran Rubén Darío, exponente del modernismo hispanoamericano, en el prefacio a Cantos de vida y esperanza: "Si en estos cantos hay política, es porque aparece universalmente" (Darío, 1989, p. 325). No se trata de ideologizar políticamente el arte, y menos de tratar de encontrar ideología política en aquellos obras que no son portadoras de esta, pero tampoco negar las mediaciones de lo ideológico-político en las expresiones artísticas que las tienen. Es pertinente aclarar que lo político no es la razón de ser del arte como manifestación de la cultura, mas no se puede obviar su presencia en reconocidas obras de arte de todos los tiempos, como lo revela la historia del arte. Propugnó que la "la teoría estética puede servir, entonces, para disipar la niebla que la ideología tiende sobre las funciones del arte, el papel del artista, las relaciones entre el arte y la sociedad, entre la obra artística y el mercado, etcétera" (Sánchez, 1992, p. 34). Y, precisamente, uno de los puntos nodales de su teoría estética tiene esa dimensión, de aclarar las nieblas que se han vertido sobre el lugar, o mejor dicho, los lugares de las mediaciones de la ideología política en el arte.

Justamente, en la interacción arte-ideología política, Sánchez Vázquez hace una aportación capital. En un conjunto de trabajos, explicó que la obra de arte entendida como totalidad concreta, abierta y dinámica permite semióticamente la comunicación artista-obra-cocreador, dándose en ella cuatro instancias ideológicas (Sánchez, 
1987, t. 1, pp. 274-280): la ideología político-general, la ideología política del autor, la ideología política en la obra de arte y la ideología estética que comprende, a su vez, la ideología artística. Concepción que no tiene otra similar, solo se acerca a ese punto de vista teórico-estético el francés Jacques Aumont en su libro La imagen (1992, pp. 200, 211, 216, 277 y 317), de 1990, pero no alcanza la sistematicidad, la profundidad y el alcance heurístico de la concepción del Adolfo Sánchez Vázquez desarrollada desde la década de 1980.

En cuanto al carácter controvertido en torno a la ideología, sobre todo la política, comenzó por aclarar su etimología inicial dada por Destutt de Tracy, al referir este que la ideología era la ciencia de las ideas, la cual permitía dar organización y cierta sistematicidad al conocimiento proveniente de lo sensorio-perceptual. Y algo queda de aquel origen, sin llegar a ser ciencia. Por su parte, Sánchez Vázquez esclareció que, en el marxismo originario, es decir, de Marx y Engels (a pesar de las diferencias entre el uno y el otro), la ideología no es solo falsa conciencia o conciencia invertida, como se plantea en La ideología alemana, sino también sistema de ideas y teoría que expresa los intereses de determinadas clases y grupos sociales en condiciones concretas, condicionada por un tipo de sociedad. Y como sistema de ideas, conceptos, principios y valores coherentemente estructurados, que conforman una teoría, con una determinada finalidad práxica; de modo genérico, puede hablarse con pertinencia de diferentes formas o tipos de ideología, filosófica, política, jurídica, religiosa, económica, estética, artística, etc., por lo que es inexacto filiar o identificar la ideología con la política, porque sería un craso error y un reduccionismo epistemológico.

En diferentes momentos de su trayectoria filosófica, teórica y estética, abordó la cuestión de la ideología general en el orden político-social, aquella que se torna dominante en un tipo de sociedad concreta, sin negar otras ideologías en ella que llegan a conflictuar o discrepar de la dominante, pudiéndose apreciar en Sánchez Vázquez una rectificación de algunos aspectos de su definición, que en lo medular fue mantenida.

La ideología general —en la acepción político-social_ es definida por él como

a) un conjunto de ideas acerca del mundo y de la sociedad que: b) responde a intereses, aspiraciones o ideales de una clase social en un contexto social dado y que: c) guía y justifica un comportamiento práctico de los hombres acordes con esos intereses, aspiraciones o ideales. (Sánchez, 1983, p. 145) 
Sin embargo, esta concepción mantenida, en lo principal desde finales de la década de 1960 hasta la década de los ochenta, sufrió modificación. Tiene que ver con la modificación de la definición anterior la polémica en relación con la ideología sostenida con el filósofo mexicano Luis Villoro (1985). Ahora, sostendrá que la ideología “1) sirve al interés de una clase o grupo social; 2) entraña una crítica, o valoración negativa, de lo existente y una valoración positiva, en un proyecto, de lo que aún no es, y 3) guía un comportamiento práctico respecto del presente y del futuro. Solo un concepto amplio de ideología, que ponga en relación esos tres aspectos, puede albergar en sus seno creencias como las estéticas, morales y liberadoras o revolucionarias sin necesidad de alojarlas en el borroso campo terciario de lo no científico ni ideológico" [las cursivas son mías] (Sánchez, 2004, p. 527). Una lectura atenta, con uso de la comparación, permite ver que, en la segunda definición de inicio de la década de 1990, el "clasismo" o metafísica clasista como principio rector fue modificado, al señalar que la ideología guía y orienta, no solo la actividad de las clases sociales, sino también la de otros grupos que no constituyen propiamente clases sociales, pues por importante que sea el papel de las clases sociales hay otros grupos en la sociedad que desempeñan papeles importantes, incluso desde el punto de vista de las transformaciones, como actores. Igualmente, entre sus componentes, no solo argumentó la existencia de ideas o conceptos, sino también de valoraciones y de creencias. Incluso, explicitará: “Si la ideología no es ciencia ni es reductible a ella, cumple siempre una función cognoscitiva del mundo, así como de las relaciones con él, y de los hombres entre sí” (Sánchez, 2004a, p. 522), al ser portadora de "ideas, valores o fines" (Villoro, 2004e, p. 529), por lo que, según su punto de vista, la ideología, no solo comprende lo discursivo epistémico, sino también lo axiológico, al contener y representar valores, valoraciones y creencias, religiosas o laicas. Perspectiva que lo llevó a destacar la importancia de la dimensión ideológica de la moral o lo estético. Componente axiológico de la ideología también presente en Umberto Eco, sobre todo en Lector in fabula, de 1979 (Eco, 1993, pp. 248-256), aunque en verdad no desarrolló aquí esta dimensión, y la refirió más bien a lo moral que a los estético.

Por su parte, Sánchez Vázquez aducirá que el “valor estético como el ideológico” (1984, p. 142) pueden estar fundidos, integrados o separados y manifestar de modo peculiar sus especificidades e interacciones. Esto le permitió analizar varios casos de cómo la ideología general, ya en el orden filosófico-cultural o político-social impacta y deja huellas significativas en la creación estético-artística, para rechazar o propugnar un proyecto de sociedad. Son los casos examinados por él de El ingenioso hidalgo don Quijote de la Mancha, de Miguel de Cervantes, El sueño, de sor Juana Inés de la Cruz; 
la estética y pintura de Diego Rivera; o la poesía de Antonio Machado. A más de otros comentarios referidos a Máximo Gorki, Bertolt Brecht o Pablo Picasso.

Entre estos análisis resulta significativa su interpretación del Quijote, de Cervantes, ensayo que tituló La utopía de don Quijote, de 1990. Comenzó por reiterar su tesis de que toda obra de arte nace condicionada por su sociedad, época, espacio y tiempo, pero la trasciende por la capacidad de dialogar con otros tiempos y circunstancias. De aquí que las preguntas debían estar dirigidas a la obra misma, más que a su autor, porque un objeto estético, una vez producido, adquiere una vida autónoma, y se independiza de la vida de su autor. Afirmó que "distinguimos, por tanto, entre las ideas encarnadas, formadas en la obra, y las ideas que el autor pretendió encarnar o formar. O también, entre las intenciones y propósitos — si es que se tiene acceso a ellos-y sus resultados" (Sánchez, 2004a, p. 531), “a pesar de” o “contra de”. Por consiguiente, la respuesta habría que buscarla en la obra misma, en su texto, en su organización interna.

Recordó estudios de la ejemplar parodia que contiene, a su vez, casi todos los géneros de lo cómico. Comenzó con Heine, quien refirió que la locura del Quijote radicaba en que quiso introducir demasiado pronto el porvenir en el presente; o Miguel de Unamuno, el cual preguntaba a la obra por el ser de España, el quijotismo como hambre de inmortalidad y ansia de libertad. Mas, Sánchez Vázquez centró su interpretación en la concepción de la utopía, de la que el Renacimiento, preámbulo de la modernidad, fue pródigo; basta recordar la de Tomás Moro o Tomás Campanella, por lo que el Quijote se inscribiría en esa tendencia. Puntualizó que si la utopía designa el no hay lugar, también indica que es posible y deseable este, por su contraste con lo real, por confrontación dialéctica entre el topo y la utopía, entre la realidad existente y la posibilidad de superarla, la cual entraña una crítica de lo existente. Se trataría de una utopía concreta, a diferencia de la utopía abstracta, según la distinción tipológica de Ernst Bloch. Subrayó que "la sociedad utópica parece estar dibujada con toda nitidez en el discurso de don Quijote a los cabreros, en el capítulo XI de la primera parte del clásico texto. Aquí se refiere que, en aquella sociedad o época en que se vivía, se ignoraban las palabras de tuyo y mío. Eran en aquella santa edad todas las cosas comunes; a nadie le era necesario tomar lo de otro, pues pertenecía a todos. La justicia estaba en sus propios términos, sin que la osasen turbar ni ofender los del favor y los del interés, que tanto ahora la menoscaban, turban y persiguen. De aquí concluyó Sánchez Vázquez que "es indudable que en la utopía de don Quijote está la idea de una sociedad futura" (Sánchez, 2004f, p. 337). Sin duda, aquí se valida su concepción de que la ideología, 
político-general, implica una crítica, ya como valoración negativa, de lo existente y una valoración positiva, como proyecto, de lo que aún no es, pero está llamado a existir.

También la ideología político-general, a nivel contextual, puede incidir en la obra de arte, así se explica, en parte, el carácter hierático del arte egipcio en la época de los faraones, la influencia de la religión en el arte románico y el arte gótico de la Edad Media, la razón de por qué Beethoven dedicó una sinfonía a Napoleón: La heroica, cuando este era un general revolucionario, que, a decir de Hegel, era la libertad montada a caballo. O Andrés Bello (cfr. Rojas, 2011, pp. 154-158) con sus silvas americanas: Alocución a la poesía y La agricultura en la zona tórrida, con las que argumentó, no solo la emancipación de España, sino de modo más amplio la ratificación de un proyecto o programa de independencia cultural para la América ibérica, el cual ya se había previsto en la primera etapa de la Ilustración hispano- portuguesa-americana (cfr. Rojas, 2011, pp. 93-130; Rojas, 2016, pp. 101-128).

Por otra parte, en cuanto a la ideología del autor, especificó: "Por ideología del autor entendemos la que él comparte, la que preexiste a su trabajo creador independientemente de cómo se logre encarnar en su obra; es la ideología con la que se acerca a la realidad y trata de representarla" (Sánchez, 1984d, p. 182). Esta viene a ser el modus vivendi de la ideología político-general u otra que el artista convierte en modus operandi de su quehacer político. En casos de artistas orgánicos como Picasso, la ideología del autor deviene ideología de la obra, como se aprecia en Guernica o Los coreanos masacrados, tragedias de condena a las guerras de la primera mitad del siglo XX, la una fascista y la otra de hegemonía de una gran potencia contra una nación tercermundista de Asia. Interacción o coincidencia de ideología política personal con equivalencia a la plasmada en las obras, de acuerdo con el idiolecto de corpus llamado Picasso. O como en Alejo Carpentier, con las novelas El recurso del método y La consagración de la primavera, con la primera caracterizó al "tirano ilustrado" de América Latina de todos los tiempos, en particular los tiranos contemporáneos, en actitud crítica y de rechazo. Y con la segunda, tipificó el proceso de consolidación de la Revolución cubana del 1 de enero de 1959, con la cual se identificó y sirvió. Mediación ideológica filtrada a través de la estética de lo real maravilloso americano como tipo de realismo literario.

Pero la complejidad de la ideología en las mediaciones del arte es diversa, y no siempre existe correspondencia de la ideología política del creador con la ideología política vertida en la obra, si la tuviese, porque hay casos en que la ideología personal del autor 
es diferente de la ideología materializada en la obra de arte, tal como sucede en los casos de Honoré de Balzac o León Tolstói, este último considerado por su obra espejo de la Revolución rusa, la de 1905 a 1907, en tanto en lo personal tuvo más bien una ideología conservadora puesto que la ideología política de Balzac era legitimista-aristocrática. Sin embargo, en La comedia humana, puso en ridículo y condenó por caduca la aristocracia, así la objetividad crítico-artística superó las limitaciones ideoclasistas del autor, por lo que su obra contradice su ideología como modus vivendi.

En su tipología Sánchez Vázquez, refirió asimismo la ideología en la obra de arte, al acotar que "por ideología de la obra entendemos la ideología ya formada como aspecto inseparable de ella, ideología que puede expresar la del autor, desviarse de esta e incluso contradecirla" (1984, p. 182). Testimonian este tipo de ideología político-social en la obra los ejemplos referidos de Balzac y Tolstói. El propio Sánchez Vázquez utiliza a modo de demostración obras del ruso Nikolai Gogol y el mexicano José Revueltas.

En cuanto a Gogol fijó su atención en El inspector, texto de teatro con el cual se flagela a manera cáustica la trivialidad y la corrupción de la que es portador un personaje como Jlestakov, que está asociado a la falta de principios de la clase dominante, por su bajeza moral. Constituye El inspector, sin duda, una sátira social punzante que cuestionó el régimen zarista de la servidumbre en nombre de una Rusia democrática. Por contrapartida, en Taras Bulba y Mirgorod, Gogol hizo brillar las virtudes del pueblo, a la vez que también denunció la mutilación de la existencia humana, la vida banal y los seres ramplones. También su novela El retrato muestra cómo un pintor se hace rico, traiciona la verdad en nombre de la utilidad de la ganancia y de la mercantilización del arte. Contrasta con las anteriores obras Las almas muertas, segunda parte, en que se presenta la regeneración de los personajes negativos, como los terratenientes, mediante la moralización y la religión. Su propuesta: ¡Sed almas vivas, no muertas!

En general, puede afirmarse de la obra de Gogol que mostró las miserias del régimen zarista y el carácter malsano de los funcionarios del sistema, especie de realismo crítico que puso al descubierto los vicios, la corrupción, el oportunismo y bajezas de Jlestakov, Chichikov, Sobakievich, así como mostró en una galería de cuadros los propietarios de siervos: el perezoso y frívolo Manilov, el zafio Sovakievich, el mentiroso y libertino Nozdriov, el avaro Pliuchkin, la tacaña y estúpida Korobochka, el insignificante y abúlico Majuev. Igualmente, autoridades y burócratas provincianos. Toda una fauna antihumana del régimen de la servidumbre. No obstante revelar desde sus libros las 
inconsistencias del régimen zarista de la servidumbre, propugnar la defensa del pueblo y la necesidad de la democracia para Rusia frente al Estado aristocrático-patriarcal, en lo personal Gogol se opuso a solucionar los problemas de Rusia por la vía de la lucha social, tal como aconteció con las revoluciones de las primeras décadas del siglo XX. Toda esta antinomia o paradoja entre la obra y la actitud política del Gogol es expuesta por Sánchez Vázquez bajo el título de "Miseria y esplendor de Gogol" (Sánchez, 2004g, pp. 106-124).

Otro caso sintomático en el que se detuvo Sánchez Vázquez — revelador igualmente de la contradicción entre la ideología en la obra y la ideología política profesada - fue el del también escritor José Revueltas. Como militante del Partido Comunista Mexicano, Revueltas defendía la estética del realismo socialista, en tanto su novela Los días terrenales, de 1949, desmentía tal teoría. La ideología de la obra o en la obra no pertenece al realismo socialista que defendía como hombre de partido. La crítica advirtió con razón que la novela no se ajustaba a esos principios y fórmulas. Y no solo esto: descubrió una contradicción flagrante entre ideología marxista-leninista sustentada por el autor y la ideología de la obra supuestamente existencialista y "antimarxista". Frente al falso optimismo socialista, los personajes de Los días terrenales se mueven en un horizonte oscuro, sin salida concreta, donde hay angustia y desesperación que nada tienen en común con "héroes positivos" del entonces realismo socialista, remiten más a la situación límite, la desesperación, la enajenación o la angustia existencialistas. Puntualizó Sánchez Vázquez que "sus personajes piensan, se mueven, y actúan en abierta oposición a la ideología del autor" (1984c, p. 183). La obra posee una objetividad y autonomía ideo-estética más allá de la ideología comunista que profesaba por aquellos años el autor del Ensayo sobre un proletariado sin cabeza.

Concluyó Sánchez Vázquez: “Tengamos presente a este respecto que hay más unidad y coherencia en su novelística que en sus reflexiones políticas” (1984c, p. 179), no obstante la autocrítica que hizo sobre ella por presión partidista, al llegar a descalificar la novela en nombre de la estética del realismo socialista y del Diamat soviético, es decir, el llamado materialismo dialéctico.

Asimismo, explican tal tipo de ideología en la obra Los fusilamientos de Madrid, de Goya; La libertad guiando al pueblo, de Eugène Delacroix; Los supervivientes de Varsovia, de Arnold Schönberg, creador del dodecafonismo; o El grito, de Edvard Munch. Obras que revelan, por su significación, dimensiones políticas; unas como la 
de Goya y Delacroix en exhortaciones libertarias, y las Schönberg y Munch la condena ante fuerzas destructivas de lo humano. Sin ser autores connotados por sus ideas políticas personales, no dejaron de plasmar en sus creaciones lo ideológico-político inherente a sus respectivos mundos de vida. Unas y otras, más allá de sus respectivas referencias contextuales, por su valor ideo, estético son actuales, ya sea en exhortación, ya sea en denuncia permanentes.

Finalmente, con razón suficiente, Sánchez Vázquez destacó la importancia de la ideología estética, la cual como ideología específica es también un sistema de ideas, conceptos, valores y valoraciones que estructuralmente refiere un sistema categorial que deviene teoría, la cual se concreta en conceptos como lo estético, el arte, la poiesis, la aisthesis, la catarsis, la experiencia estética, la obra abierta, la creación artística, la identificación y el distanciamientos estéticos, lo trágico, la belleza, lo sublime, lo grotesco, la fealdad, lo cómico y sus especies, el gusto, la expresión, el tiempo estético, la polifuncionalidad, la recepción participante, el cocreador, y muchas más. Los artistas al producir sus obras, el público al consumirlas o el crítico al valorarlas reflexivamente se guían por determinada ideología estética, como ha ocurrido con el clasiscismo, el barroco, el romanticismo, el surrealismo, el impresionismo, las vanguardias, el deconstructivismo posmodernista, etc. Las ideologías estéticas, además, se particularizan en la literatura, la danza, las artes visuales y escénicas, el cine, la televisión, entre otras.

Las ideologías: la general, la del autor y la estética son soportes que preexisten a la ideología de la obra de arte. El error de todo contenidismo estético fue confundir el aspecto ideológico-artístico de la obra de arte con el soporte exterior a ella, con las otras ideologías, cayéndose inevitablemente en el sociológico estético reduccionista. "El arte tiene un contenido ideológico [político-social], pero solo lo tiene en la medida en que la ideología pierde su sustantividad para integrarse en esa nueva realidad que es la obra de arte. Es decir, los problemas ideológicos que el artista se plantea tiene que resolverlos artísticamente" (Sánchez, 1966, p. 44) mediante la creación, porque el ser del arte es por excelencia establecer comunicación, deleite, crítica o denuncia, en que existe una mediación entre la obra y el cocreador como receptor participante. "Si el arte es, por esencia, diálogo, comunicación, mar abierto en el tiempo y el espacio, el consumo o goce adecuado a esta producción reclama el derrumbe de todas las murallas que quieren limitar su capacidad de comunicación” (Sánchez, 1966, p. 232). Tesis de estética abierta sostenidas ya por Sánchez Vázquez en Las ideas estéticas de 
Marx, libro considerado por Teresa del Conde como "uno de los clásicos contemporáneos en materia de estética” 1985, p. 265). Y podría decirse, igualmente, que por sus contribuciones a la Estética y el Arte, con mayúsculas, Sánchez Vázquez es también un clásico contemporáneo siempre actual.

\section{Referencias}

Aumont, J. (1992). La imagen (A. López Ruiz, trad.). Barcelona, España: Paidós Ibérica.

Carrit, E. F. (1983). Introducción a la estética (O. G. Barreda, trad.). Ciudad de México, México: Fondo de Cultura Económica.

Conde, T. del (1985). Carta abierta a Adolfo Sánchez Vázquez. En J. González, C. Pereyra y G. Vargas Lozano (Eds.), Praxis y filosofía: ensayos en homenaje a Adolfo Sánchez Vázquez. Ciudad de México, México: Grijalbo.

Darío, R. (1989). Poesía. La Habana, Cuba: Arte y Literatura.

Eco, U. (1984). Obra abierta. Madrid, España: Planeta/De Agostini.

Eco, U. (1993). Lector in fabula: la cooperación interpretativa en el texto narrativo (3. ${ }^{\text {a }}$ ed., R. Pochtar, trad.). Barcelona, España: Lumen.

Fabelo, J. R. (2005). Apuntes para una interpretación axiológica del arte. En M. Sánchez Medina (Coord.). Estética: enfoques actuales. La Habana, Cuba: Félix Varela.

Foster, H. (1998), La posmodernidad (7. a ed.). Barcelona, España: Kairós.

Kagan, M. S. (1984). Lecciones de estética marxista leninista. La Habana, Cuba: Arte y Literatura.

Lyotard, J. F. (1991). La condición postmoderna: informe sobre el saber (2. ${ }^{\mathrm{a}}$ ed., M. Antolín Rato, trad.). Ciudad de México, México: Red Editorial Iberoamericana.

Plazaola, J. (1999). Introducción a la estética: historia, teoría y textos (3. ${ }^{\text {a }}$ ed.). Bilbao, España: Universidad de Deusto.

Portuondo, J. A. (1979). Orden del día. La Habana, Cuba: Unión de Escritores y Artistas de Cuba.

Rojas Gómez, M. (1996). Estética y libertad. Islas, 113. 
Rojas Gómez, M. (1998). Crisis, marxismo y estética contemporánea en América Latina. En Modernidad-postmodernidad. La Habana, Cuba: Editorial de Ciencias Sociales.

Rojas Gómez, M. (2011). Identidad cultural e integración: desde la Ilustración hasta el Romanticismo latinoamericanos. Bogotá, Colombia: Universidad de San Buenaventura.

Rojas Gómez, M. (2016). Del barroco como estilo artístico a programas culturales emancipatorios. En J. D. Huertas Ruiz (Comp.) y F. G. Púa Mora (Ed.), Retablo barroco: visiones y horizontales de lo exuberante. Bogotá, Colombia: Universidad de San Buenaventura.

Rojas Gómez, M. y Días Salas, S. (2016). Valor y valoración estético-artístico-musical de Balada de la doncella enamorada, III parte de El decamerón negro de Leo Brouwer”. Islas, 183.

Sánchez Vázquez, A. (1966). Las ideas estéticas de Marx. La Habana, Cuba: Edición Revolucionaria.

Sánchez Vázquez, A. (1978). Estética y marxismo. Tomo 1 (3. ${ }^{\mathrm{a}}$ ed.). Ciudad de México, México: Era.

Sánchez Vázquez, A. (1980). Filosofía de la praxis. Barcelona, España: Crítica.

Sánchez Vázquez, A. (1982). Antología: textos de estética y teoría del arte. Ciudad de México, México: Universidad Nacional Autónoma de México.

Sánchez Vázquez, A. (1983). Ensayos marxistas sobre filosofía e ideología. Barcelona, España: Océano.

Sánchez Vázquez, A. (1984a). De la crítica de arte a la crítica del arte. En Autor, Ensayos sobre arte y marxismo. Ciudad de México, México: Grijalbo.

Sánchez Vázquez, A. (1984b). De la imposibilidad y la posibilidad de definir el arte. En Autor, Ensayos sobre arte y marxismo. Ciudad de México, México: Grijalbo.

Sánchez Vázquez, A. (1984c). La estética terrenal de José Revueltas. En Autor, Ensayos sobre arte y marxismo. Ciudad de México, México: Grijalbo. 
Sánchez Vázquez, A. (1984d). “Notas sobre Lenin y el arte”, 1970. En Autor, Ensayos sobre arte y marxismo. Ciudad de México, México: Grijalbo.

Sánchez Vázquez, A. (1984e). “Sobre Marx y la estética marxista”, entrevista realizada por Javier Molina el 13 de marzo de 1983 para Unomásuno. En Autor, Ensayos sobre arte y marxismo. Ciudad de México, México: Grijalbo.

Sánchez Vázquez, A. (1984f). “Sánchez Vázquez y la cuestión estética”, entrevista realizada por Berta Aceves para Excelsior, el 18 de junio de 1983. En Autor, Ensayos sobre arte y marxismo, Ciudad de México, México: Grijalbo.

Sánchez Vázquez, A. (1984g). Socialización de la creación o muerte del arte. En Autor, Ensayos sobre arte y marxismo. Ciudad de México, México: Grijalbo.

Sánchez Vázquez, A. (1984h). Vanguardia artística y vanguardia política. En Autor, Ensayos sobre arte y marxismo. Ciudad de México, México: Grijalbo.

Sánchez Vázquez, A. (1987). Ideología y realismo en Marx y Engels. En Marx y la contemporaneidad. Tomo 1. La Habana, Cuba, Editorial de Ciencias Sociales.

Sánchez Vázquez, A. (1992). Invitación a la estética. Ciudad de México, México: Grijalbo.

Sánchez Vázquez, A. (1996). Cuestiones estéticas y artísticas contemporáneas. Ciudad de México, México: Fondo de Cultura Económica.

Sánchez Vázquez, A. (2004a). Claves de la ideología estética de Diego Rivera. En Autor, A tiempo y destiempo: antología de ensayos (2. ${ }^{\text {a }}$ ed., pról. de R. Xirau). La Habana, Cuba: Editorial de Ciencias Sociales.

Sánchez Vázquez, A. (2004b). El “sueño” metódico de sor Juana. En Autor, A tiempo $y$ destiempo: antología de ensayos (2. ${ }^{\text {a }}$ ed., pról. de R. Xirau). La Habana, Cuba: Editorial de Ciencias Sociales.

Sánchez Vázquez, A. (2004c). El tiempo en la poesía española. En Autor, A tiempo y destiempo: antología de ensayos (2. ${ }^{\mathrm{a}}$ ed., pról. de R. Xirau). La Habana, Cuba: Editorial de Ciencias Sociales.

Sánchez Vázquez, A. (2004d). Humanismo y visión de España en Antonio Machado. En Autor, A tiempo y destiempo: antología de ensayos (2. ${ }^{\mathrm{a}}$ ed., pról. de R. Xirau). La Habana, Cuba: Editorial de Ciencias Sociales. 
Sánchez Vázquez, A. (2004e). La crítica de la ideología en Luis Villoro. En Autor, A tiempo y destiempo: antología de ensayos (2. ${ }^{\mathrm{a}}$ ed., pról. de R. Xirau). La Habana, Cuba: Editorial de Ciencias Sociales.

Sánchez Vázquez, A. (2004f). La utopía de Don Quijote. En Autor, A tiempo y destiempo: antología de ensayos (2. ${ }^{\text {a }}$ ed., pról. de R. Xirau). La Habana, Cuba: Editorial de Ciencias Sociales.

Sánchez Vázquez, A. (2004g). Miseria y esplendor de Gogol. En Autor, A tiempo y destiempo: antología de ensayos (2. ${ }^{\text {a }}$ ed., pról. de R. Xirau). La Habana, Cuba: Editorial de Ciencias Sociales.

Sánchez Vázquez, A. (2004h). Octavio Paz en su "Laberinto". En torno a "El laberinto de la soledad" medio siglo después”. En Autor, A tiempo y destiempo: antología de ensayos (2. ${ }^{a}$ ed., pról. de R. Xirau). La Habana, Cuba: Editorial de Ciencias Sociales.

Sánchez Vázquez, A. (2004i). Vida y filosofía. En Autor, A tiempo y destiempo: antología de ensayos (2. a ed., pról. de R. Xirau). La Habana, Cuba: Editorial de Ciencias Sociales.

Sánchez Vázquez, A. (2005). De la estética de la recepción a la estética de la participación. Ciudad de México, México: Universidad Nacional Autónoma de México.

Villoro, L. (1985). El concepto de ideología y otros ensayos. Ciudad de México, México: Fondo de Cultura Económica.

Xirau, R. (2004). Prólogo a Adolfo Sánchez Vázquez. En A tiempo y destiempo: antología de ensayos (2. ${ }^{\mathrm{a}}$ ed.). La Habana, Cuba: Editorial de Ciencias Sociales.

Warning, R. (Comp.) (1989). Estética de la recepción. Madrid, España: Visor.

Welsh, W. (2011). Actualidad de la estética, estética de la actualidad (M. T. Ortega, trad.). La Habana, Cuba: Centro Teórico-Cultural Criterios. 